\title{
Sensitivities of sulfate aerosol formation and oxidation pathways on the chemical mechanism employed in simulations
}

\author{
A. F. Stein ${ }^{1}$ and R. D. Saylor ${ }^{2}$ \\ ${ }^{1}$ ERT, Inc. on assignment to the Air Resources Laboratory (ARL), NOAA, College Park, MD, USA \\ ${ }^{2}$ Air Resources Laboratory (ARL), NOAA, Atmospheric Turbulence and Diffusion Division, Oak Ridge, TN, USA
}

Correspondence to: A. F. Stein (ariel.stein@noaa.gov)

Received: 23 February 2012 - Published in Atmos. Chem. Phys. Discuss.: 26 March 2012

Revised: 30 August 2012 - Accepted: 31 August 2012 - Published: 25 September 2012

\begin{abstract}
The processes of aerosol sulfate formation are vital components in the scientific understanding of perturbations of earth's radiative balance via aerosol direct and indirect effects. In this work, an analysis of the influence of changes in oxidant levels and sulfur dioxide oxidation pathways was performed to study the underlying pathways for sulfate formation. Sensitivities of this constituent were calculated from a series of photochemical model simulations with varying rates of $\mathrm{NO}_{\mathrm{x}}$ and $\mathrm{VOC}$ emissions to produce variations in oxidant abundances using a photochemical model (CMAQ) that covers the eastern US for part of the ICARTT 2004 campaign. Three different chemical mechanisms (CBIV, CB05, and SAPRC99) were used to test model responses to changes in $\mathrm{NO}_{\mathrm{x}}$ and VOC concentrations. Comparison of modeled results and measurements demonstrates that the simulations with all three chemical mechanisms capture the levels of sulfate reasonably well. However, the three mechanisms are shown to have significantly different responses in sulfate formation when the emissions of $\mathrm{NO}_{\mathrm{x}}$ and/or VOC are altered, reflecting different photochemical regimes under which the formation of sulfate occurs. Also, an analysis of the oxidation pathways that contribute to sulfur dioxide conversion to sulfate reveals substantial differences in the importance of the various pathways among the three chemical mechanisms. These findings suggest that estimations of the influence that future changes in primary emissions or other changes which perturb $\mathrm{SO}_{2}$ oxidants have on sulfate abundances, and on its direct and indirect radiative forcing effects, may be dependent on the chemical mechanism employed in the model analysis.
\end{abstract}

\section{Introduction}

Since the 1970s, studies of particle sulfate $\left(\mathrm{SO}_{4}^{2-}\right)$ formation and fate have played a key role in advancing the scientific understanding of diverse phenomena such as acid precipitation, tropospheric particle matter composition, and, more recently, in the role $\mathrm{SO}_{4}^{2-}$ particles play in the direct and indirect forcings of the earth's radiative budget. The study of the formation of $\mathrm{SO}_{4}^{2-}$ aerosols involves a complex coupling among gas- and aqueous-phase photochemical reactions and meteorological processes. Formation of $\mathrm{SO}_{4}^{2-}$ is chemically linked to primary emissions of sulfur dioxide $\left(\mathrm{SO}_{2}\right)$ and to the abundance of atmospheric oxidants such as hydroxyl radical $(\mathrm{OH})$, hydrogen peroxide $\left(\mathrm{H}_{2} \mathrm{O}_{2}\right)$, ozone $\left(\mathrm{O}_{3}\right)$, methylhydroperoxide (MHP), and peroxyacetic acid (PAA) (Seinfeld and Pandis, 1998). All of these oxidant species are formed via photochemical reactions which originate from emissions of nitrogen oxides $\left(\mathrm{NO}_{\mathrm{x}}\right)$ and volatile organic compounds (VOC). Therefore, it is expected that variations in primary emissions of $\mathrm{NO}_{\mathrm{x}}$ and VOCs may have an effect on the amount and distribution of sulfate (Stein and Lamb, 2002).

The aim of this work was to investigate the dependency of sulfate formation on oxidant levels and on the choice of the chemical mechanism employed to describe the processes by which these oxidants are produced. Towards that end, we present simulated $\mathrm{SO}_{4}^{2-}$ concentrations calculated using a three-dimensional regional air quality model with three different photochemical mechanisms and compare results with airborne in situ measurements. Changes in the amount of primary emitted $\mathrm{NO}_{\mathrm{x}}$ and VOC were then introduced for each mechanism to understand the responses of sulfate formation processes to variations in $\mathrm{SO}_{2}$ oxidant concentrations. 

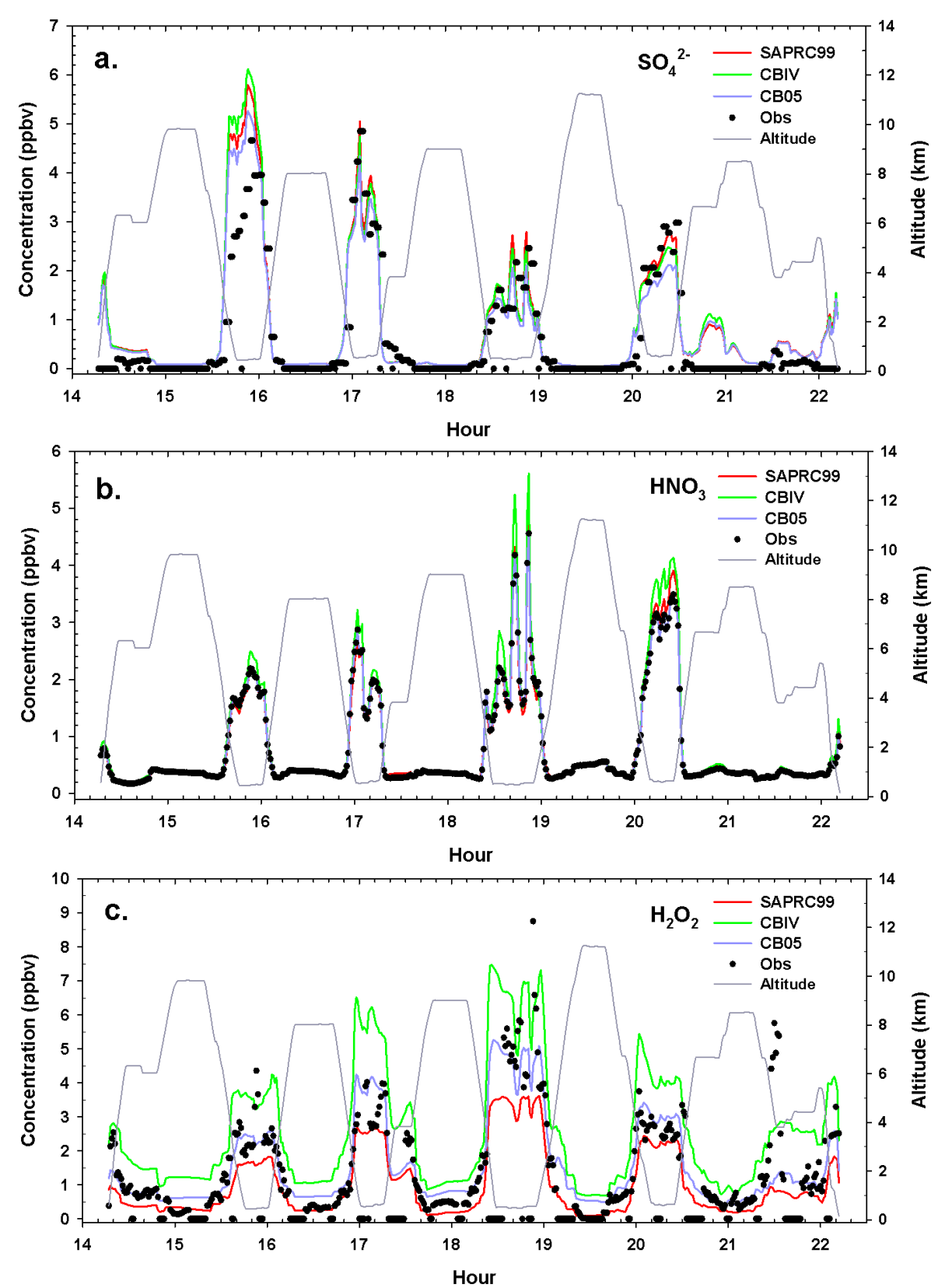

Fig. 1. Comparison of modeled vs. observed (a) $\mathrm{PM}_{2.5}$ sulfate; (b) total nitrate; and, (c) hydrogen peroxide concentrations along the path of the DC8 flight on 20 July 2004.

In addition, an oxidation partitioning analysis was performed to delineate the main oxidation pathways participating in the conversion of gas-phase $\mathrm{SO}_{2}$ to particle $\mathrm{SO}_{4}^{2-}$ for each chemical scheme.

\section{Model and measurements}

The Community Multiscale Air Quality (CMAQ) modeling system (Byun and Schere, 2006) Version 4.6 was used to simulate the study period that extended from 14-23 July 2004.
This modeling period encompasses three flights that took place on 18,20, and 22 July 2004, corresponding to a portion of the International Consortium for Atmospheric Research on Transport and Transformation (ICARTT) field campaign (Fehsenfeld et al., 2006). The flight patterns corresponding to the study period have been described in Singh et al. (2006). The model configuration included 3-D advection, cloud processes, gas and aqueous chemistry, cloud scavenging and wet and dry deposition. Three different chemical mechanisms were used to test model responses to changes in $\mathrm{NO}_{\mathrm{x}}$ and 

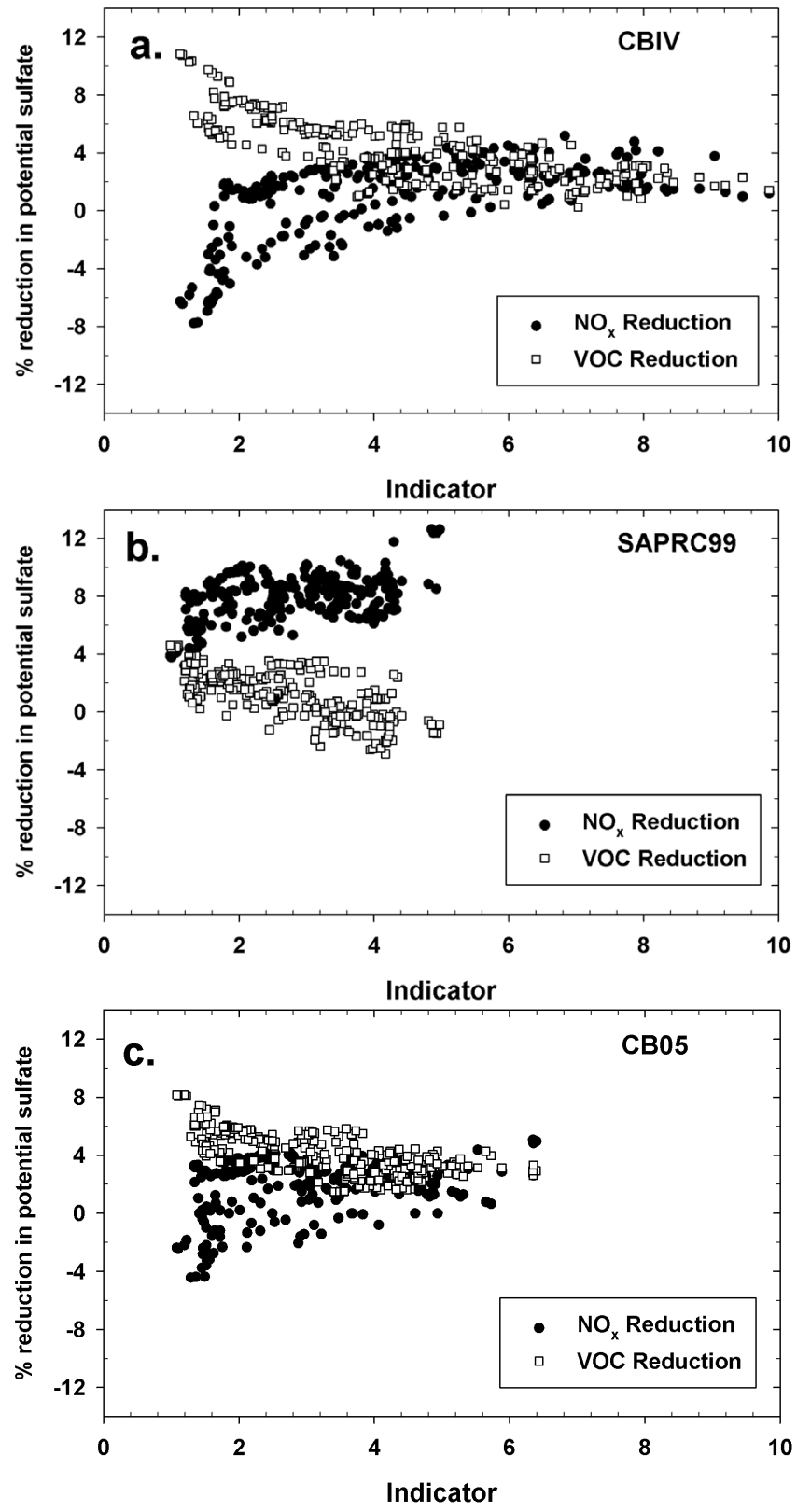

Fig. 2. Normalized percentage response of potential sulfate concentrations to changes in $\mathrm{NO}_{\mathrm{x}}$ and $\mathrm{VOC}$ as a function of $I_{\mathrm{SO}_{4}}=$ $\left\{\left[\mathrm{H}_{2} \mathrm{O}_{2}\right]+\left[\mathrm{SO}_{4}^{2-}\right]\right\} /\left\{\left[\mathrm{HNO}_{3}\right]+\left[\mathrm{NO}_{3}^{-}\right]\right\}$for (a) CBIV; (b) SAPRC99; and, (c) CB05 for data along the path of the DC8 flight on 18, 20, and 22 July 2004.

VOC emission rates, namely CBIV (Gery et al., 1989), CB05 (Yarwood et al., 2005), and SAPRC99 (Carter, 2000). The aerosol calculation is based on the ISORROPIA v1.7 model (Nenes et al., 1998) and the aqueous phase simulation includes uptake of gases into the cloud droplets, aqueous oxidation of $\mathrm{SO}_{2}$ by $\mathrm{H}_{2} \mathrm{O}_{2}, \mathrm{O}_{3}$, MHP, PAA, and catalytic oxidation by iron and manganese (Binkowski and Roselle, 2003) and wet scavenging. The model domain covered the East- ern US with a horizontal resolution of $12 \mathrm{~km}$ and 22 vertical layers of variable thickness. The meteorological data for this study was based on Eta model (Black, 1994) outputs linked to the CMAQ modeling system using the methodology described in Otte et al. (2005). Emissions include point, mobile, area, and biogenic sources (Mathur, 2008). The area emissions are based on the 2001 National Emissions Inventory. Emissions of $\mathrm{SO}_{2}$ and $\mathrm{NO}_{\mathrm{x}}$ from point sources were projected from 2001 to 2004 based on the Department of Energy's 2004 Annual Energy Outlook. Mobile sources were estimated based on the MOBILE6 model (Pouliot and Pierce, 2003) and biogenic emissions were calculated with the BEIS3.12 model (Pierce et al., 2002).

The measurements used for this study from the ICARTT field campaign were obtained from http://www-air.larc.nasa. gov/cgi-bin/arcstat. Results for 18, 20, and 22 July 2004, along the path of the DC8 flight have been utilized in this analysis. Since the aim of this study is focused on sulfate formation, only species relevant to its formation have been included in the comparison. A more complete chemical comparison of CMAQ model results with ICARTT measurements can be found elsewhere (Yu et al., 2010).

Sulfate- $\mathrm{NO}_{\mathrm{x}}-\mathrm{VOC}$ sensitivities were calculated from a series of photochemical model simulations with varying $\mathrm{NO}_{\mathrm{x}}$ and VOC emission rates to produce responses in oxidant abundances. For each chemical mechanism three simulations were performed: a base case simulation, a simulation with $35 \%$ reduction in anthropogenic $\mathrm{NO}_{\mathrm{x}}$ emissions, and a simulation with $35 \%$ reduction in anthropogenic VOC emissions.

\section{Discussion}

Comparison of base case model results and measurements demonstrates that all three chemical mechanisms capture the levels of boundary layer $\mathrm{H}_{2} \mathrm{O}_{2}, \mathrm{SO}_{4}^{2-}$ and total nitrate (nitric acid/nitrate) $\left(\mathrm{HNO}_{3} / \mathrm{NO}_{3}^{-}\right)$within $50 \%$ for 20 July 2004 (Fig. 1). (All results presented in this work for July 20 are representative of similar results obtained for July 18 and 22, which are not shown for brevity.) These results are consistent with the model comparisons performed by Yu et al. (2010) for the same dataset. In particular, it is important to notice that all three chemical mechanisms show a very similar performance with regard to fine particle sulfate, with the largest differences occurring in the boundary layer where concentrations are highest. At their largest, the differences in sulfate between the mechanisms are less than $20 \%$. The similar sulfate concentrations obtained with the three different chemical mechanisms suggest that oxidant-limited conditions (i.e. the $\mathrm{SO}_{2}$ oxidation is limited by the oxidant availability) prevailed during the study period. Therefore, a sensitivity analysis and an $\mathrm{SO}_{2}$ oxidant partitioning study were undertaken to investigate whether or not the three mechanisms form these similar sulfate concentrations via similar underlying processes. 

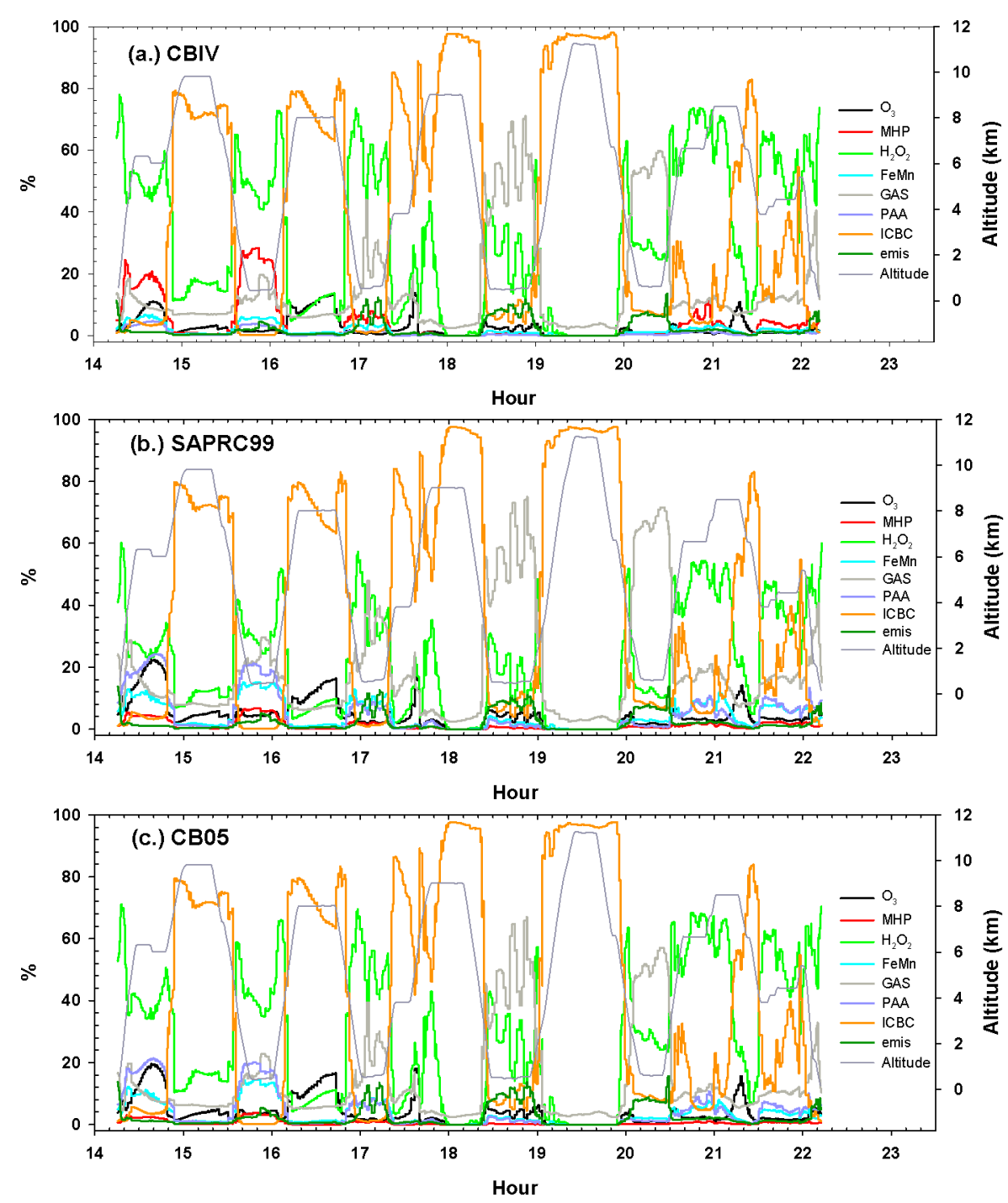

Fig. 3. Percent contribution of sulfate formation pathways to total sulfate for (a) CBIV, (b) SAPRC99, and (c) CB05 along the path of the flight of the DC8 on 20 July 2004. In the legend: ICBC stands for initial conditions and boundary conditions.

In order to analyze the response of sulfate levels to changes in primary emissions of $\mathrm{NO}_{\mathrm{x}}$ and VOCs, Stein and Lamb (2002) proposed the use of a combination of afternoon concentrations of $\mathrm{HNO}_{3}, \mathrm{H}_{2} \mathrm{O}_{2}$, and $\mathrm{SO}_{4}^{2-}$ as "indicator species" of ambient "potential" $\mathrm{SO}_{4}^{2-}-\mathrm{VOC}-\mathrm{NO}_{\mathrm{x}}$ sensitivities, where potential sulfate is defined here, after Stockwell (1994), as $\left[\mathrm{SO}_{4}^{2-}\right]+\left[\mathrm{H}_{2} \mathrm{O}_{2}\right]$. The concept of potential sulfate was first proposed by Stockwell et al. (1988) and can be interpreted as the maximum concentration of $\mathrm{SO}_{4}^{2-}$ that could be produced in the gas and aqueous phases. This idea provides an integrated tool to deal with this complex chemical system. The link between the indicator ratio (defined as $\left\{\left[\mathrm{H}_{2} \mathrm{O}_{2}\right]+\left[\mathrm{SO}_{4}^{2-}\right]\right\} /\left\{\left[\mathrm{HNO}_{3}\right]+\left[\mathrm{NO}_{3}^{-}\right]\right\}$and hereafter denoted as $\mathrm{I}_{\mathrm{SO}_{4}}$ ) and $\mathrm{NO}_{\mathrm{x}}$-VOC chemistry can be understood in terms of the dominant sinks and sources for odd-hydrogen. A $\mathrm{NO}_{\mathrm{x}}$-sensitive regime, defined as the chemical conditions conducive to a stronger decrease in potential sulfate as a result of a $\mathrm{NO}_{\mathrm{x}}$ reduction when compared with the same reduction in VOC (see Sillman, 1995 and Stein and Lamb, 2002), favors the formation of potential sulfate over the production of $\mathrm{HNO}_{3}$. Under this condition, the production of $\mathrm{H}_{2} \mathrm{O}_{2}$ constitutes the main loss of $\mathrm{HO}_{\mathrm{x}}$ and the gas-phase $\mathrm{SO}_{2}$ oxidation is favored over the formation of $\mathrm{HNO}_{3}$. On the other hand, the VOC-sensitive regime, featuring a reduction in potential sulfate when reducing VOC and an increase in potential sulfate as $\mathrm{NO}_{\mathrm{x}}$ is lowered, is characterized by a higher production rate of $\mathrm{HNO}_{3}$ that overwhelms the formation of potential sulfate. Therefore, larger values of $I_{\mathrm{SO}_{4}}$ are associated with $\mathrm{NO}_{\mathrm{x}}$-sensitive conditions while smaller values for the indicator are associated with VOC sensitive regimes.

Figure 2 presents the normalized percentage reduction in $\left\{\left[\mathrm{H}_{2} \mathrm{O}_{2}\right]+\left[\mathrm{SO}_{4}^{2-}\right]\right\}$ (i.e., potential sulfate) concentration 
as a consequence of either a $\mathrm{NO}_{\mathrm{x}}$ or a VOC emission reduction for each chemical mechanism along the path of the DC8 flights for 18, 20, and 22 July 2004. The difference in potential sulfate levels between the base case and the $\mathrm{NO}_{\mathrm{x}}$ and VOC reduction scenarios is plotted as a function of the simultaneously modeled $I_{\mathrm{SO}_{4}}$, $\left\{\left[\mathrm{H}_{2} \mathrm{O}_{2}\right]+\left[\mathrm{SO}_{4}^{2-}\right]\right\} /\left\{\left[\mathrm{HNO}_{3}\right]+\left[\mathrm{NO}_{3}^{-}\right]\right\}$. Although each particular chemical mechanism shows a distinct response to $\mathrm{NO}_{\mathrm{x}}$ and VOC changes, the shape of the sensitivity curves depicted in Fig. 2 share some common general features arising from the sensitivity of $\mathrm{HO}_{\mathrm{x}}$ to changes in $\mathrm{NO}_{\mathrm{x}}$ levels for all the chemical mechanisms. Each curve shows that for relative low values of $I_{\mathrm{SO}_{4}}$ (i.e. less than approximately 4, 1, and 3 for CBIV, SAPRC-99, and CB05, respectively) the potential sulfate concentrations tend to decrease when VOC levels are reduced and tend to increase when a reduction in $\mathrm{NO}_{\mathrm{x}}$ levels occurs. This is, by definition, a VOC sensitive regime. Under these conditions, lowering VOC in the photochemical system will reduce $\mathrm{HO}_{x}$ producing less $\mathrm{H}_{2} \mathrm{O}_{2}$. Furthermore, a reduction in $\mathrm{NO}_{\mathrm{x}}$ increases the availability of $\mathrm{HO}_{\mathrm{x}}$, that otherwise will form $\mathrm{HNO}_{3}$, to form peroxides instead, therefore increasing the potential sulfate.

Even though VOC sensitive conditions exist for the three mechanisms, when comparing Fig. 2a, b, and c it can be observed that the range indicator values for which VOC conditions prevail differ among the mechanisms with $I_{\mathrm{SO}_{4}}$ values lower than about 4,1 , and 3 for the CBIV, SAPRC99, and CB05 chemical mechanisms, respectively. Differences in these values cannot be attributed to a single component of the chemical mechanisms but to a complex interrelation among the radical cycles depicted by each mechanism. For instance, the increasingly higher formation rate of $\mathrm{H}_{2} \mathrm{O}_{2}$ from the SAPRC-99, CB05, and CBIV mechanisms (Luecken et al., 2008) explains the higher simulated $\mathrm{H}_{2} \mathrm{O}_{2}$. Since in the CBIV mechanism the formation of $\mathrm{H}_{2} \mathrm{O}_{2}$ is the only sink of $\mathrm{HO}_{2}$ a decrease in $\mathrm{NO}_{\mathrm{x}}$ will free up more $\mathrm{HO}_{\mathrm{x}}$ that will directly form even more $\mathrm{H}_{2} \mathrm{O}_{2}$. In CB05 and SAPRC-99, on the other hand, the formation of organic peroxides diverts $\mathrm{HO}_{2}$ from forming $\mathrm{H}_{2} \mathrm{O}_{2}$, leading to less potential sulfate formation. The three chemical mechanisms give a more convergent picture when modeling $\mathrm{HNO}_{3}$, with the CBIV mechanism producing slightly more than the other two. SAPRC-99 and CB05 produce similar $\mathrm{HNO}_{3}$ levels (Fig. 1b) because in SAPRC-99 the reaction rate for the formation of $\mathrm{HNO}_{3}$ is lower but the $\mathrm{OH}$ levels are higher than in CB05 (Luecken et al., 2008). Therefore, when combining the increasingly higher $\mathrm{H}_{2} \mathrm{O}_{2}$ peroxide formation from CBIV, CB05 and SAPRC-99 with a small variation in the $\mathrm{HNO}_{3}$ among the three mechanisms we end up with increasingly higher values of $I_{\mathrm{SO}_{4}}$. Indeed, the linear regression coefficient of the $I_{\mathrm{SO}_{4}}$ calculated with the three chemical mechanisms against measurements shows values of $1.15,0.79$, and 0.89 for CBIV, SAPRC-99 and CB05, respectively.

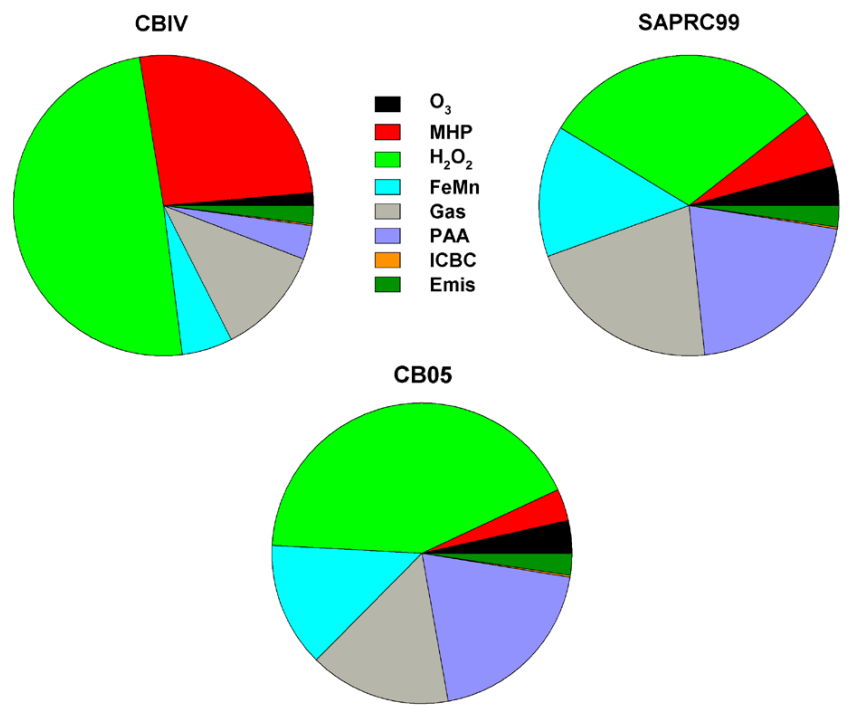

Fig. 4. Pie chart showing the percent contribution of sulfate formation pathways to total sulfate for CBIV, SAPRC99, and CB05 on 20 July 2004 at 15:45.

Conversely, for $I_{\mathrm{SO}_{4}}$ values higher than 7, 2, and 5 for CBIV, SAPRC-99 and CB05, respectively, the curves in Fig. 2 show features corresponding to NOx sensitive conditions, i.e. potential sulfate is reduced more when $\mathrm{NO}_{\mathrm{x}}$ levels are reduced than when VOC are. Differences in the VOC speciation and more reactivity of the aromatic fragments (Faraji et al., 2008) can help explain why the SAPRC-99 mechanism tends to show more $\mathrm{NO}_{\mathrm{x}}$-sensitivity than the $\mathrm{CB} 05$ and CBIV. In SAPRC-99, the relative higher abundance of reactive VOC species with respect to $\mathrm{NO}_{\mathrm{x}}$ leads to VOC saturated conditions. Under these conditions, a reduction in $\mathrm{NO}_{\mathrm{x}}$ slows down the cycling between $\mathrm{HO}_{2}$ and $\mathrm{OH}$ lowering the formation of potential sulfate (Stein and Lamb, 2002).

The three chemical mechanisms exhibit markedly different responses in potential sulfate formation when emissions of $\mathrm{NO}_{\mathrm{x}}$ and VOC are altered; these differing responses reflect different photochemical regimes under which the formation of sulfate occurs with the three chemical mechanisms. Therefore, for a given change in oxidation conditions, (i.e. changes in solar radiation, seasons, primary emissions, etc.) the three chemical mechanisms will produce substantially different responses in sulfate formation. In particular, the SAPRC99 chemical mechanism shows that reductions in $\mathrm{NO}_{\mathrm{x}}$ are more effective in reducing $\mathrm{H}_{2} \mathrm{O}_{2}+\mathrm{SO}_{4}^{2-}$ than are reductions in VOCs. On the other hand, results using CBIV show that $\mathrm{H}_{2} \mathrm{O}_{2}+\mathrm{SO}_{4}^{2-}$ will be reduced more effectively if VOCs are reduced. Finally, the CB05 chemical mechanism exhibits an intermediate behavior somewhere between the other two mechanisms but with closer similarities to CBIV given their common formulation. 


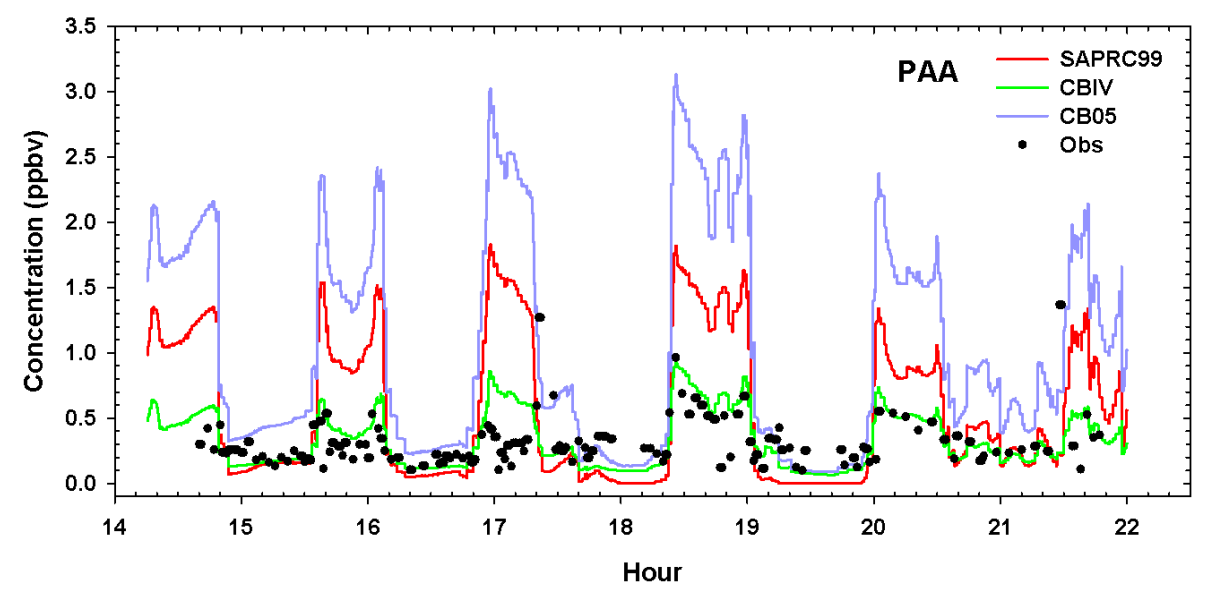

Fig. 5. Comparison of modeled and observed PAA concentrations for CBIV, SAPRC99, and CB05 along the path of the flight of the DC8 on 20 July 2004.

Theoretical, as well as model-derived, estimates of the threshold value of $I_{\mathrm{SO}_{4}}$ for the transition from $\mathrm{VOC}$ to $\mathrm{NO}_{\mathrm{x}}$ sensitivity in the formation of potential sulfate were derived by Stein and Lamb (2002) to range from 1.4 to 2.2. In that work, the SAPRC99 chemical mechanism was used and the period of study was from 14-16 July 1995, covering the eastern US. Figure $2 b$ shows that when SAPRC99 is used, the indicator transition seems to be in agreement with the estimated values from Stein and Lamb (2002). On the other hand, Fig. 2a and c shows that the transition has approximate values of 7 and 5 for the CBIV and the CB05 chemical mechanisms, respectively.

The main chemical processes that drive behavior of the $\mathrm{SO}_{4}^{2-}-\mathrm{VOC}-\mathrm{NO}_{\mathrm{x}}$ sensitivities for the three chemical mechanisms are expected to be the gas-phase oxidation by $\mathrm{OH}$ and the aqueous-phase oxidation mediated by $\mathrm{H}_{2} \mathrm{O}_{2}$ while other oxidants are expected to play a minor role (Seinfeld and Pandis, 1998). To determine the importance of the different formation pathways, the sulfate tracking diagnostic model configuration included in CMAQ (Mathur et al., 2008) was employed. Significant differences in sulfate production chemical pathways are observed to be present between the CBIV, CB05, and SAPRC99 mechanisms (Fig. 3). In general, for all three chemical mechanisms, oxidation pathways for $\mathrm{SO}_{2}$ are dominated by the gas-phase $\mathrm{OH}$ and the aqueousphase $\mathrm{H}_{2} \mathrm{O}_{2}$ reactions. However, for the CBIV mechanism, up to $30 \%$ of sulfate formation occurs through aqueous phase oxidation by methylhydroperoxide (MHP) from 15:30 to $16: 00$ p.m. (Figs. 3a and 4). Comparison with measured MHP concentrations shows that the model (using CBIV) tends to overestimate levels of MHP by as much as an order of magnitude (not shown). Furthermore, for the CB05 and the SAPRC99 mechanisms, the aqueous $\mathrm{SO}_{2}$ oxidation pathway mediated by peroxyacetic acid (PAA) accounts for up to $20 \%$ of the sulfate formation from 15:30 to 16:00 p.m. (Figs. 3b, c and 4). Comparison of PAA concentrations with observed values indicates that the model (using CB05 or SAPRC-99) tends to overestimate the levels of PAA by as much as 4 times the observed values (Fig. 5). This can be understood in terms of the stoichiometric parameters used to describe the formation of PAA though the reaction of peroxyacetyl radical (PA) and $\mathrm{HO}_{2}$. In CB05 and SAPRC99, 0.8 and 0.75 PAA molecules are formed for each $\mathrm{PA}+\mathrm{HO}_{2}$, respectively, while for the CBIV mechanism only 0.21 PAA are formed. When interpreting these results it has to be taken into account that CBIV, CB05, and SAPRC-99 are condensed mechanisms that have originally been developed to model ozone concentrations and its precursors (mostly focused on hydrocarbons and $\mathrm{NO}_{\mathrm{x}}$ ) by replicating smog chamber experiments. The use of lumping techniques to condense the complex atmospheric processes into these chemical mechanisms produces reasonably good representations of the ozone formation (Carter, 2010). However, the description of the formation of other species, like PAA, does not appear to be as accurate.

\section{Conclusions}

This study illustrates that, despite the close agreement between the observed and simulated sulfate concentrations, each of the three chemical mechanisms presents a different sensitivity response of sulfate formation to changes in oxidant levels. The SAPRC99 mechanism generally presents sulfate levels that are $\mathrm{NO}_{\mathrm{x}}$ sensitive along the path of the flights for the cases analyzed. On the other hand, CBIV and CB05 show VOC sensitivity to be dominant for the formation of sulfate. In addition, beyond the dominant pathways for $\mathrm{SO}_{2}$ to sulfate conversion (aqueous $\mathrm{H}_{2} \mathrm{O}_{2}$ and gaseous $\mathrm{OH}$ oxidation), different secondary sulfate formation pathways are simulated among the three chemical mechanisms. For CBIV, the aqueous phase oxidation via MHP constitutes 
the third dominant reaction while for SAPRC99 and CB05 aqueous oxidation via PAA dominates.

These findings imply that good agreement between measured and modeled concentrations is a necessary but not a sufficient condition for an accurate depiction of sulfate chemical formation processes. Indeed, recent studies (e.g. Goto et al., 2011) highlight the importance of an accurate description of sulfate formation chemical pathways, in particular in global aerosol models. The more detailed formulation of sulfate chemical processes presented in Goto et al. (2011) showed an improvement in simulation performance when compared with observations and revealed a difference of approximately $50 \%$ in the estimated radiative forcing with respect to the very simplified approaches generally utilized in the global simulations included in the IPCC-AR4 report. However, as shown in the present work, simulations of sulfate may agree with the measured values despite the use of completely different chemical mechanisms and consequent differing formation pathways. Our analysis of the influence of changes in oxidant levels and $\mathrm{SO}_{2}$ oxidation pathways strongly suggests that the choice of chemical mechanism may produce noticeable differences in sulfate distributions given changes in primary emissions of $\mathrm{NO}_{\mathrm{x}}$ or VOCs, or given some other change which affects the amount or relative concentrations of $\mathrm{SO}_{2}$ oxidants. This implies that estimations of the influence of future changes in emissions on sulfate levels, and therefore on its direct or indirect radiative forcing effects, may be highly dependent on the chemical mechanism employed in the model analysis. Giving the limited time and space scales examined in the present study, further research is needed to establish the extent of influence of these findings in a global-scale modeling framework and to determine what impacts of these sensitivities may be potentially propagated to long-term climate scenario analyses.

An additional conclusion that can be drawn from this work is one which is well known among three-dimensional atmospheric chemistry modelers in the context of tropospheric ozone simulation, namely that the right answer can be obtained for the wrong reasons. In other words, compensating errors within the modeling framework can lead to results which compare well with measurements, but the model errors can remain hidden unless the right measurement-model comparisons are undertaken. In this work, we have identified a potential source of compensating errors in the simulation of fine particle sulfate. Further research is necessary to understand the full implications of this finding.

Acknowledgements. The authors like to thank Shaocai Yu for facilitating the emission and meteorological data as well as part of the software used to extract the data from the model. Daewon Byun (1956-2011) is also acknowledged for helpful discussions. This work was funded in part by the US Weather Research Program.

Edited by: B. Ervens

\section{References}

Binkowski, F. S. and Roselle, S. J.: Models-3 community multi-scale air quality (CMAQ) model aerosol component: 1. Model description, J. Geophys. Res., 108, 4183, doi:10.1029/2001JD001409, 2003.

Black, T.: The new NMC mesoscale Eta Model: description and forecast examples, Weather Forecast., 9, 265-278, 1994.

Byun, D. W. and Schere, K. L.: Review of governing equations, computational algorithms, and other components of the models3 Community Multiscale Air Quality (CMAQ) modeling system, Appl. Mech. Rev., 59, 51-77, 2006.

Carter, W. P. L.: Implementation of the SAPRC-99 Chemical Mechanism into the MODELS-3 Framework, United States Environmental Protection Agency, 2000.

Carter, W. P. L.: Development of the SAPRC-07 chemical mechanism, Atmos. Environ., 44, 5324-5335, 2010.

Faraji, M., Kimura, Y., McDonald-Buller, E., and Allen, D.: Comparison of the Carbon Bond and SAPRC photochemical mechanisms under conditions relevant to southeast Texas, Atmos. Environ., 42, 5821-5836, doi:10.1016/j.atmosenv.2007.07.048, 2008.

Fehsenfeld, F. C., Ancellet, G., Bates, T. S., Goldstein, A. H., Hardesty, R. M., Honrath, R., Law, K. S., Lewis, A. C., Leaitch, R., McKeen, S., Meagher, J., Parrish, D. D., Pszenny, A. A. P., Russell, P. B., Schlager, H., Seinfeld, J., Talbot, R., and Zbinden, R.: International Consortium for Atmospheric Research on Transport and Transformation (ICARTT): North America to Europe Overview of the 2004 summer field study, J. Geophys. Res., 111, D23S01, doi:10.1029/2006JD007829, 2006.

Gery, M. W., Whitten, G. Z., Killus, J. P., and Dodge, M. C.: A photochemical mechanism for urban and regional scale computer modeling, J. Geophys. Res., 94, 12925-12956, 1989.

Goto, D., Nakajima, T., Takemura, T., and Sudo, K.: A study of uncertainties in the sulfate distribution and its radiative forcing associated with sulfur chemistry in a global aerosol model, Atmos. Chem. Phys., 11, 10889-10910, doi:10.5194/acp-1110889-2011, 2011.

Luecken, D. J., Phillips, S., Sarwar, G., and Jang, C.: Effects of using the CB05 vs. SAPRC99 vs. CB4 chemical mechanism on model predictions: Ozone and gas-phase photochemical precursor concentrations, Atmos. Environ., 42, 5805-5820, 2008.

Mathur, R.: Estimating the impact of the 2004 Alaskan forest fires on episodic particulate matter pollution over the eastern United States through assimilation of satellite-derived aerosol optical depths in a regional air quality model, J. Geophys. Res., 113, D17302, doi:10.1029/2007JD009767, 2008.

Mathur, R., Roselle, S., Pouliot, G., and Sarwar, G.: Diagnostic Analysis of the Three-Dimensional Sulfur Distributions over the Eastern United States Using the CMAQ Model and Measurements from the ICARTT Field Experiment. Air Pollution Modeling and Its Application XIX, NATO Sci. Peace Secur., 5, 496504, doi:10.1007/978-1-4020-8453-9_54, 2008.

Nenes, A., Pilinis, C., and Pandis, S. N.: Continued Development and Testing of a New Thermodynamic Aerosol Module for Urban and Regional Air Quality Models, Atmos. Environ., 33, 1553-1560, 1998.

Otte, T. L., Pouliot, G., Pleim, J. E., Young, J. O., Schere, K. L., Wong, D. C., Lee, P.C. S., Tsidulko, M., McQueen, J. T., Davidson, P., Mathur, R., Chuang, H., DiMego, G., and Seaman, N. L.: Linking the Eta model with the Community Multiscale Air 
Quality (CMAQ) modeling system to build a national air quality forecasting system, Weather Forecast., 20, 367-384, 2005.

Pierce, T., Geron, C., Pouliot, G., Kinnee, E., and Vukovich, J.: Integration of the biogenic emission inventory system (BEIS3) into the community multiscale air quality modeling system, preprints, 12th Joint Conference on the Apps. of Air Pollut. Meteor. with the A\&WMA, on Am. Meteorol. Soc., Norfolk, Va., 20-24 May 2002, J85-J86, 2002.

Pouliot, G. and Pierce, T.: Emissions processing for an air quality forecasting model, 12th Intl. Conf. on Emission Inventories, San Diego, Calif., 28 April-1 May, 2003.

Seinfeld, J. H. and Pandis, S. N.: Atmospheric Chemistry and Physics: From Air Pollution to Climate Change, John Wiley \& Sons, Inc., New York, 1998.

Sillman, S.: The use of $\mathrm{NO}_{y}, \mathrm{H}_{2} \mathrm{O}_{2}$, and $\mathrm{HNO}_{3}$ as indicators for ozone- $\mathrm{NO}_{\mathrm{x}}$-hydrocarbon sensitivity in urban locations, J. Geophys. Res., 100, 14175-14188, 1995.

Singh, H. B., Brune, W. H., Crawford, J. H., Jacob, D. J., and Russell, P. B.: Overview of the summer 2004 Intercontinental Chemical Transport Experiment - North America (INTEX-A), J. Geophys. Res., 111, D24S01, doi:10.1029/2006JD007905, 2006.
Stein, A. F. and Lamb, D.: Chemical Indicators of Sulfate Sensitivity to Nitrogen Oxides and Volatile Organic Compounds, J. Geophys. Res., 107, 4449, doi:10.1029/2001JD001088, 2002.

Stockwell, W. R.: The effect of gas-phase chemistry on aqueousphase sulfur dioxide oxidation rates, J. Atmos. Chem., 19, 317329, 1994.

Stockwell, W. R., Milford, J. B., McRae, G. J., Middleton, P., and Chang, J. S.: Nonlinear coupling in the $\mathrm{NO}_{\mathrm{X}}-\mathrm{SO}_{\mathrm{x}}$ reactive organic system, Atmos. Environ., 22, 2481-2490, 1988.

Yarwood, G., Rao, S., Yocke, M., and Whitten, G. Z.: Updates to the Carbon Bond Chemical Mechanism: CB05, RT-04-00675, Final Report to U.S. Environmental Protection Agency, Yocke and Company, Novato, CA, December, 2005.

Yu, S., Mathur, R., Sarwar, G., Kang, D., Tong, D., Pouliot, G., and Pleim, J.: Eta-CMAQ air quality forecasts for $\mathrm{O}_{3}$ and related species using three different photochemical mechanisms (CB4, CB05, SAPRC-99): comparisons with measurements during the 2004 ICARTT study, Atmos. Chem. Phys., 10, 30013025, doi:10.5194/acp-10-3001-2010, 2010. 